DOI: 10.1515/abcsj-2016-0019

\title{
Us and Them: A Vision of Heroes on the Move in John McGahern's Fiction
}

\author{
DANA RADLER \\ Bucharest University of Economic Studies
}

\begin{abstract}
Current explorations of migration in fiction focus on innovative perspectives, linking memory and trauma with the concepts of exile and conflict. Personal memories ask for an understanding of what belonging and identity represent for the Irish; immigration has hybrid and fertile links to memory studies, psychology and psychoanalysis (Akhtar), making the immigrant both love and hate his new territory, while returning to the past or homeland to reflect and regain emotional balance. From the focus on 'the sexy foreigner' (Beltsiou), we rely on the idea of crisis discussed by León Grinberg and Rebeca Grinberg, Frank Summers' examination of identity, the place of the modern polis and the variations of the narrative (Phillips), the trans-generational factor (Fitzgerald and Lambkin), the departure seen as an exile (Murray and Said) and the impact of guilt (Wills).

Such views support an analysis of McGahern's writing which works as a blend of memories and imagination, the writer highlighting dilemmas, success and failure as ongoing human threads. They are as diverse as the people met by the novelist in his youth, many of them being workers, nurses, entrepreneurs, teachers and writers, both young immigrants in search of a better life and migrants returning to spend their retirement or holidays home.
\end{abstract}

Keywords: Irishness, anxiety, exile, conflict, irony, self, guilt, identity, circularity, existence.

\section{Introduction: traditional and hybrid views}

Irish communities have been for over half a century now the heart of deep changes as a result of economic influences and people's need to find a 
more prosperous, stable living, aligning their status and changing religious options to those of the overseas nations following the post-world war era. The key to understanding this process needs to start from a preliminary examination of what migration stands for: it has been defined as "the geographical mobility of persons who move, either individually, in small groups, or in large masses and remain in their new environment for a sufficiently long time to make a home there and carry out the activities of daily living" (Grinberg and Grinberg 155), while Julia Beltisou highlights the "exciting narrative of the sexy foreigner," claiming that it "co-exists with the painful experiences of unbelonging, non-recognition, struggle, alienation and trauma" (1). Søren Frank looks at the topic and defines it from the perspective of a migration literature emerging from the Greek antiquity and heroes such as Daedalus and Odysseus seen as individual resilient experiences implying a deep and irreversible transformation. $\mathrm{He}$ examines several contemporary authors, using a departure point defined as Ansatzpunkt by Erich Auerbach in the early fifties, and draws on the capacity of migration to act as a 'synthesizer,' relying on its ability to unite sociology and aesthetics (5-6), yet pointing out that fiction based on migration cannot be looked upon from a post-colonialist standpoint only, though this brings a valuable insight; instead, he supports a more comprehensive approach which has to extend beyond the rather eurocentric and historical context of Western Europe and find equally vibrant sources and expressions in languages and literatures other than English, German or French.

In terms of needs, migration has been seen and discussed in the last decade as a predominantly hybrid trend, linking postcolonial identity studies with memory studies, and also as a highly expressed psychological drive, since León Grinberg and Rebeca Grinberg suggest that it relates to a number of complex manifestations specific to a crisis, while observing the changes experienced by the migrant, as he becomes gradually more focused on his new life, and begins to leave behind a series of mental associations and representations:

[It] triggers different types of anxieties in the person who emigrates: separation anxiety, persecutory anxiety arising from the confrontation with the new and the unknown, depressive anxiety over loyalties and values 
which give rise to mourning for objects left behind and for the lost parts of the self, and confusional anxieties arising from failure to discriminate between the old and the new. (154)

The members of his initial place of departure undergo their own transformation, and the result is a gradual detachment and increasing distance, while the departed hero remains attached to the non-human environment which remains for several years a stable source for his identity and personal reflection.

In what concerns one's feelings and their flow in the recently shaped social and economic circumstances, Grindberg and Grindberg show that a whole series of confusional anxieties arise in the mind of the immigrant, placing him in a potentially oedipal triangular case where the hero faces two different parents, namely the two countries he relates to. He leads them to a symbolically-built space "evoking ambivalence and conflict of loyalties" (161), but that needs a highly flexible cultural toolkit, one able to shift perspective and employ a diversity of tools, such as the comparative analysis of migratory trajectories and the "continuities and discontinuities" in fiction (Frank 13).

In their analysis of this phenomenon as a robust and resilient stream in the mind, the two authors also suggest that "Paranoid anxieties can develop into true panic when the immigrant confronts the overwhelming demands that he must meet: loneliness, ignorance of the language, finding work and a place to live, etc." (161). They think that the immigrant endures high stress in his new homeland, and that gradually "guilt takes different forms varying from the normal to the highly pathological" (162) in his effort to deal with such alienating stress. The further the new location and difference in terms of social patterns, economic prospects or cultural value, the higher and more durable becomes his endeavor to "adapt to the new conditions, struggling against confusion, and this causes him to turn again and again to dissociations" (162). The adjustment to the new place implies painful choices, from the moment the person decides to relocate his existence elsewhere; and the impact on what is coined as 'identity' by cultural contributors suffers equally profound transformations: "[i]n order to become integrated into the environment 
where he is received, the immigrant must renounce part of his individuality, at least temporarily" (162).

What surfaces from recent contributions examining the psychoanalytical research body is the need to widen the lens of the approach, to welcome a wider and more systematic, historically and anthropologically speaking, approach to those undergoing such changes, as Frank Summers shows when he refers to its needs to "move away from the monadic theory of the mind, not only because it artificially separates person from world, but also because it disconnects the patient from a heritage that can be crucial for the formation of her identity" (2). It is not only this trans-generational element that often defines migration and identity studies, but also the process which, as Fitzgerald and Lambkin suggest, revolves around a complex trajectory: leaving, crossing and arriving or a 'basic three-stage structure' specific to any human journey (16).

Quoted in Tony Murray's study on London Irish Fictions: Narrative, Diaspora and Identity, Edna O'Brien defines the departure as a separation or exile: "Writers are by nature exiles. Sometimes it's voluntary exile. Sometimes you have to leave your own country. But in order to write about something, whatever it be, there has to be that rupture, that terrible separation, because it is in that separation that the depth and profoundness and everything else returns to one" (5). In his effort to examine the case of Irish writers present on London sites, Murray defines the framework as being heavily marked by the movement between the two backgrounds, a movement which impacts the very identity of the migrant: "migrants move between two sets of subjects who 'stay put', those in their place of origin and those in their place of destination," and this finally determines the protagonist to "negotiate the often contested allegiances of diaspora space that this entails" (12).

The case of Irish immigrants definitely shares similarities with other migrations, and knows differences as well, depending on geographical conditions, the opportunities of immigrants to re-visit and reconnect with their original hometown and the guilt or shame perceived about the native culture, seen in the new context as retrograde, oldfashioned and inappropriate for survival and prosperity. In her book 
devoted to the study of post-war Irish immigration, Clair Wills suggests that its representation in fiction followed a strong existentialist and realist touch, and investigates McGahern's prose as an example of declared 'British Palladies' in which she immediately detects the "frustration and deprivation of Irish society" in stories about heroes leaving Ireland behind, taking the experience of abused protagonists close to French naturalism. In her view, such young and active "would-be modern young men and women" (106) are deeply connected to and correspondingly shape the cultural milieu they were extracted from "as characters [meant to] battle with the poverty of imaginative resources" (106).

Looking at the attractiveness of London sites for newcomers, Lawrence Philips explains its relatively recent newness, many of these contemporary metropolitan additions being practically produced in the last hundred years, since post-war writers were attracted by its "distinctive fabric and image" (2), observing the variations of the narrative upon the city in the works of various contemporary writers, particularly the "convergence between time and space in the city-which encompasses both the image of the city and its past" (4).

Such views support an analysis of McGahern's writing in which we look at how fiction works as a blend of memories and imagination, the writer being interested in highlighting dilemmas, success and failure as ongoing threads of the life of his protagonists. They are as diverse as the people met by the novelist in his youth, many of them being workers, nurses, entrepreneurs, teachers and writers, both young immigrants in search of a better life and migrants returning to spend their retirement or holidays at home.

\section{Migration Topoi: Shaping the Past}

In their contributions to immigration studies emerging from psychological and psychoanalytic work, researchers reviewed by Salman Akhtar brought to the surface of a human's mind an interwoven series of concepts playing a key role in John McGahern's fiction as well, for instance the waking screen, discussed by Joseph Kepecs and Joseph Slap, noting the experience of a fetus perceiving a blurred reality. Bernard Pacella was to 
expand the concept, observing the role of early external experience, such as smell, sounds, skin colours of significant others, type of trees and houses (Comprehensive Dictionary of Psychoanalysis 306). In his studies focusing on immigrants, Akhtar nuances these implications upon a child's early understanding, observing that "non-human elements (e.g. toys, crib, blanket, home, trees, local animals, the street on which the family lives, regional landscape, and even sounds and climate that are typical of the early environment) also contribute" in shaping his overall perception (5).

Yet migration also works as a cultural gate allowing access to knowledge, better working prospects and improved living standards. For Irish migrants in the 1950s, England was a highly detested colonial presence, and, paradoxically, the place where one could find decent work and pay. As Linda Nochlin observes in her chapter on Art and the Conditions of Exile: Men/Women, Emigration/Expatriation, artists also perceived it quite differently from other compatriots: "exile, at least in so far as the work is concerned, seem to be less traumatic" (Suleiman 37). In McGahern's own words, that encounter was not seen as a source of dislocation and insatisfaction; on the contrary, he enjoyed the initial contact with the territory of great intellects: "I was absolutely amazed to set foot in England for the first time because to me this was the land of Shakespeare and Wordsworth. I would have read many English classics, and for me it was like stepping on sacred soil" (Collinge and Vernadakis 4). As Ben Forkner detects, such a move brings, from a creator's point of view, clear benefits: a higher freedom from home-sourced limits, as well as valuable moral support and lasting friendships. In McGahern's case, his first summer spent away did not make him return home hastily to the place where he spent his childhood while his father was a Garda officer, and he describes it with a typical humorous note:

I really was fed up of home-I didn't want to see the barracks again. When I was well known, about fifteen years ago, a deputation came from Cootehall village, wanting me to buy the barracks and set myself up as some kind of a monument there. I told them that I had spent almost twenty years trying to get out of the place, and that I had no intention of buying my way back in. (4) 
This did not impede the writer to return to his experience there time and again while living abroad for several decades; but that was a completely different mission than resetting himself in a familiar, once restricted background. After years spent away, he plainly confesses in his last volume, Memoir, that his second wife, Madelaine, fully accepted and enjoyed the idea of buying a small property in Leitrim and spend together most of their time there: "I came back to live among these lanes thirty years ago. My wife and I were beginning our life together, and we thought we could make a bare living on these small fields and I would write. It was a time when we could have settled almost anywhere, and if she had not liked the place and the people we would have moved elsewhere" (Memoir 2). This return was possible for several reasons: the distance in time helped relieving certain painful wounds and lasting conflicts; his early years in England did entail work, financial or relationship hardships, reaching a peak with McGahern's exile because of the banning of his second novel, The Dark, in 1965, on alleged grounds of impure representations of Catholic priests, as well as the effect of his marriage with a Finnish, non-Catholic divorcee, Annikki Laaksi the same year, two elements the Catholic Church could not accept as compatible with a teaching career. Yet, in the years following the banning, once the writer was less under the impact of such difficult circumstances, and was increasingly recognized as an authentic and remarkable voice of the Anglo-Irish writing, his own rapport with the past changed, allowing him to cast a rather detached, occasionally ironic, and often realist vision of exile. After the mid-seventies, the novelist embarked on a differentlyfragmented kind of life in which writing and travelling were intertwined "with stints as visiting professor or writer-in-residence at various Irish, American or Canadian universities" (McCarthy 26).

When returning to the past, environmental change and alienation are the core elements of change included in McGahern's introductory piece to The Collected Stories published in 1992: Wheels is the title of the first story and it starts and ends with the image of rattling wheels. For the novelist, wheels turn into a highly suggestive metaphor, working along three lines of interpretation: 
a) A predictable hint to the passage of time, implying a circular physical movement and the associated noise of metal wheels, suggested by the very opening line: "Grey concrete and steel and glass in the slow rain drip of the morning station, three porters pushing an empty trolley up the platform" (The Collected Stories $3)$;

b) A suggestion of human futility, an individual who failed to achieve something lasting or valued by companions; the clue lies in the "empty trolley up on the platform" line followed shortly by a mention about a void existence: "nothing but wait and watch and listen" (3); from this point of view, critics have noted a certain, permeable yet distinct "affirmation of McGahern's own humanistexistentialist values and beliefs at the outset of his writing life" (McCarthy 59);

c) A rather constant immature status, the hero continues his unformed fetus-like posture despite his attempts to reject his own expected existentialist failure: "the story too close to the likeness of my own life for comfort though" but continues to laugh at his own position by taking the overheard story as a suitable conversation topic with fellows in the pub: "it'd do to please Lightfoot in the pub when I got back" (The Collected Stories 3).

On the other hand, Beltsiou practically notes that if immigration studies have benefited from a theoretical corpus built in the last couple of years, the body under scrutiny is not as clearly defined as expected by theorists, and suggests the main reason to lie in the line of generation authorship since "second-generation authors" are still perceived as creators of immigration literature (4). A secondary issue to which she points is language: is immigration literature authorship as credible and valuable if written in a non-native language by exploring the position of "a dialogue with our new culture or to the ones we left behind in our native country?" (4). Perhaps the answer is as ambivalent and ambiguous as the status of the immigrant whose identity shifts from one territory to the other.

Leaving home is painful for most heroes in Irish fiction; they perceive it as exile, endure increasing loneliness and suffer the effects of a 
fragmented existence in a new urban context, where work against pay turns into an unstoppable drive. In the case of McGahern's protagonists, such an estrangement is manifested back at home too, especially based on a long-term encounter with the Anglo-speaking world. Heroes have noted the superior, critical perspective of affluent, often middle- or upper-class members, and express their personal dissatisfaction with a direct, humorous yet serious touch: "The ignorance and boredom of the people of this part of the country is appalling, simply appalling," Boles mimicked the English accent quietly. "That's the speech he'll make to Peter at the gate. A strange person" (The Collected Stories 13) is the comment made by a local to Colonel Sinclair, an absent protagonist in this story, whose name and reference suggest a rather patronizing, inflexible, unsociable individual.

\section{The Tide That Emptied the Countryside}

In McGahern's stories depicting young workers on London building sites, several themes emerge and shape their lives: alienation, lack of education and prospects, shallow sexual satisfaction, an ongoing drive to earn one's living in precarious working conditions, and limited social interaction. Heroes sell their long hours of work against an amount which usually allows them to return home and impress their relatives and old friends, spending lavishly what was earned after one year of toil. Their new, apparently prosperous living prospects place them in a difficult relationship with their homeland and old connections: they long for it, but hate to live there, and sometimes we have a glimpse upon a resulted fractured identity: they dislike some of their new social relationships, yet find themselves incapable of being at peace with their native space. In this context, the clash between generations, authority and domination over youth and autonomy becomes a genuine source of suffering and distress; the loss of big possessions left behind is complemented by an equally devastating case of missing small, apparently less significant items, associated with old memories, as Akthar observes: "Loss of such objects threatens to wreck the intrapsychic relationship bridges" until heroes feel "existentially naked and robbed of subjective continuity" (Immigration 
and Acculturation: Mourning, Adaptation and the Next Generation 7). Moreover, members of one's family and hometown perceive a similar emotional rupture, as they tend to look on the returns of the young generations as boastful, lacking respect, and incapable of acknowledging the contribution of their parents.

This is the very heart of such a fissure in family relationships emerging in "Gold Watch," published in The New Yorker in 1980 and included in several collections of stories. In looking at this story, Michael C. Prusse examines the implications of a home-paid visit by a not-soyoung man returning with his lover, first in Kilkenny "where she had grown up" (The Collected Stories 212), and then, a few weeks later, to his father's house, a visit which "turned to a far worse disaster than [he] could have envisaged" (213). Prusse notes that the man returning to his father's home claims "an old golden watch, which he remembers from the days of his boyhood" and that by doing that the young male hero takes it "as his heirloom" (3). The understanding of his gestures needs to be examined along several kinds of reading where the first layer is represented by social relationships, as we learn from the story that the old father is able of highly aggressive acts, and that the son is unable to mitigate a growing irritation between the woman who accompanies him and who is seen as an inappropriate life partner because of her age. The father becomes so ill-mannered that he voices a reproachful comment against her oldness: "What age is your intended? She looks well on her way to forty" (The Collected Stories 213). As the son does not manage to hide this offence, his female companion turns completely upset, and the man convinces her, with clear difficulty, to stay overnight. His effort to make her understand the aggression of his aging father is reflected upon as an inevitable envy upon which one needs to find his own sources of protection and mental sheltering: "You live in too many eyes-in envy or confusion or even simple admiration, it's all the same" (214). At this point, the conflict with the elder generation forces the main protagonist to find refuge and sharpen his intellectual devices, from compliments meant to bring peace to his lover's mind to silence and politeness used "like a single weapon" (214) against the invader, in this case the parental host. This develops the confrontation so much more difficult for the male hero, 
because the father knows very well that he plays on his own territory, and the familiarity of these surroundings allows him to burst into such unexpected acts. In the end, when the son tries to regain his father's friendliness by bringing an expensive, modern watch as a peace offering, brought to forget the battle axe, the father violently dismisses this attempt taken as a new affront, by using it at work, hoping it will break from violent shakes, and in the end simply drops it into "a tar barrel with water for spraying potatoes" (224) thinking that the blue stone added that very afternoon will ultimately ruin the device. During the night, the son goes out into "a perfect moonlight night" and the serenity of the moment is interrupted by his discovery of the watch in the barrel, still ticking. The son's inner confession, "What shocked me was that I felt neither surprise nor shock" (225) cannot be read as a mere acceptance of the fact; the conflict between the two figures is far from an end, and this temporarily suspended conflict is suggested briefly by the opposition between the silence of the moment and the dying ticking of the timepiece: "The ticking of the watch down in the barrel was so completely muffled by the spray that only by imagination could it be heard. A bird moved in some high branch, but afterwards the silence was so deep it began to hurt, and the longing grew for the bird or anything to stir again" (225).

A different side of the same issue, migrants going and returning in the fifties, is questioned and revealed in "Oldfashioned" (included in The Collected Stories), where we have a fresh insight into Anglo-British relationships: the Sinclairs are a couple who give up their house in Wimbledon, buy the old parsonage in Ardcarne and settle in a quiet, cosy life, except their two-month regular visits to their daughter in Durham. Although locals adjust to their presence, their lifestyle is far from everyone else's and that is sharply commented on: “They're strange. They're different. They're not brought up the like of use. Those hot climates they get sent to do things to people" (252). There is a doubtful feeling, an attitude split between tolerance and spite, partly influenced by a genuine interest in what stands for a superior civilization; the Sinclair couple is associated with the upper class, with refined, rather outdated taste, and an inclination to change their current setting but not by investing directly in locals. When speaking about Mrs Sinclair and her 
unusual habit of enjoying a drink outside the bar, while the Colonel would bring her the glasses through the car window, and when asked by Charlie, the bar tender, his wife would not join a more comfortable seat in the bar; this is explained gently but firmly: "She'd not like that. Women of her generation were brought up never to set foot in bars, and the matter ended there, and though it caused a veritable hedgerow of talk for a few weeks, it provoked no laughter" (252). After the Sergeant from the barracks helps the Colonel with a gun licence formalities, the spouse appears with a "large basket of apples to the barracks" (253) and soon gets the Sergeant's permission to have his son's help around their garden. As the story develops, it seems that all parties get a higher interest in each other and that the boy's work releases a silent, ongoing tension; the father almost expects this interest to grow into a more practicable, potentially productive support or result for his descendant. But the second part of the story goes into an unexpected series of attitudes and mental clashes, and, as often in McGahern's prose, the silent pace and apparent peace of the season is not paralleled by the coming events, despite the boy's appreciation for his host's home: "The wheel of summer turned pleasantly. The seeds pushed above the ground, were thinned. [...] Beyond the order and the luxury, what he liked best about the house was the silence" (257).

In the course of the story, we gradually learn that Irish identity relies not only on self- and group-affirmation, but also on contesting the other, in this case the British intruder settled in the local milieu. The differentiation and stubborn assertion of this identity is exposed openly through a series of dichotomic oppositions: "There was no idle speech" (257), coming from the Sinclairs, versus the insatiable "craving for news" shared by the Guard Casey and the Sergeant: "News, any news, passing like flame from mouth to eager mouth, slowly savoured in the eyes" (250); the Catholic church displaying "its stark ugliness," compared to the beautiful stained glass "Purser windows" of the Protestant one (249); the Sinclairs travelling in their Jaguar versus the locals still using donkeys for their field work; Johnny's inability to think about his future career when asked what kind of work he thought about when finishing school: "It depends on what comes up" triggering Colonel's instant sarcasm: "What 
do you mean by what comes up?" (257); the "surprisingly exotic plants [brought] from as far away as China and India" of the nursery farm of Rockingham House estate, as opposed to the "cows and a tractor" (265) bought by the Sergeant immediately after his resignation; Colonel's fixation about time-keeping "which was in opposition to the casual local sense of coming and going, fining each man an hour's pay for every fifteen minutes late" (266).

In his study upon London-focused writing and diaspora, Murray explains, while examining The Barracks and various protagonists leaving Ireland for England and returning back home for summer visits, that McGahern's prose emphasizes "the ways in which migrant identities are configured in close if uneasy relationships between those who leave, those who stay and those who return" (96). At the end of the story, we learn that Johnny confirmed Colonel Sinclair's and Brother Benedict's expectations, got a scholarship to university and returned home "educated beyond [his] intelligence" (268), declares his father, and after several years spent on building sites, the young man completes a $\mathrm{PhD}$ and starts working for a news television station. He returns home, determined to make "a series of documentary films about the darker aspects of Irish life" (268), which equals the aim to capture a world to die, and we almost hear McGahern's own voice commenting on his hero's productions "bringing things to light that were in bad need of light," despite critical voices on such a futile focus on a vanishing world.

The story shifts from difficult relationships to difficult-to-accept changes in the whole Irish society, and the narrative highlights the sweeping wave taking so many people away and the massive economic and social changes in the reshaped Irish community:

The tide that emptied the countryside more than any other since the famine has turned. Hardly anybody now goes to England. [...] Most houses have a car and a colour television. The bicycles and horses, carts and traps and sidecars, have gone from the roads. A big yellow bus brings the budding scholars to school in the town, and it is no longer uncommon to go to university. The mail car is orange. Just one policeman with a squad car lives in the barracks. (269) 
The narrative tone stays realist and notes with mild irony the change of the local priest, whose discourse is completely different from that of his predecessors, closely followed by the change of language for religious service, observed with a straightforward relief: "Heaven is all about us, hell is in ourselves and in one moment can be exorcised. ... The altar boys kneeling in scarlet and white at the foot of the altar steps ring the bell and attend the priest, but they no longer have to learn Latin" (269). The secularization of the Catholic Church is complemented by definite changes in the living standards, often taken for improvements. The narrative voice suggests though that such changes implied a certain emotional loss too. The locals were in search of a comfortable life, close to urban standards, relieved to abandon their usual walking for miles, hard work in the fields, the familiar chat as the main socializing vehicle, or the unquestionable authority of the Church and the Garda upon all members of the community.

\section{The Self and the Other}

As Denis Sampson observes in his study of the early, formative years spent in Dublin and later in England by McGahern, the writer confessed in an interview taken in 1986 his interest in writing about real circumstances, and connecting experience with imagination in a finely-built canvas: "Everything begins as experience, how could one know anything unless one had experience? I think of writing as drawing or painting. I keep close to the way things actually happened." This is confirmed in his prose by the very recurrent presence of the Sinclairs: mentioned by two old friends, Boles and Gillespie, who refer to him as a "strange person" or simply "[t]ouched, that's all" (13), a Protestant, therefore a "strange coot" who seems to express through actions and words "Luther's idea about women. The bed and the sink. As good to engage a pig in serious conversation as a woman. All candles were made to burn before the high altar of their cunts. It was no rush of faith, let me tell you good sir, that led to my conversion. I was dragged into your holy Roman Catholic Apostolic Church by my male member" (14) comments Gillespie; and then a slightly rephrased fragment where the same episode is retold by the narrator in 
"The Conversion of William Kirkwood" to explain rare conversions of Catholics into Protestants and even rarer vice versa, one example being "the Englishman Sinclair, who had married one of the Conways" (339). In That They May Face the Rising Sun, Jamesie Murphy tells Pat Ryan about an ambush of the Black and Tans of young rebels and a similar reference emerges from old memories: "Then they came for poor Sinclair, the Protestant, nine fields away. The Sinclairs were quiet and hardworking and they kept to themselves like all the Protestants. They knew as much about the ambush we knew" (243).

In looking critically at his compatriots, McGahern the novelist constantly shifts from sympathy to irony, from realism to a passionate carpe diem vision, strategies that do not necessarily exclude each other, but which work in a contradictory, thoroughly surprising manner, meant to trigger a deeper learning out of ordinary experience. In "Faith, Hope and Charity," Cunningham and Murphy are two heroes taken from McGahern's early, difficult years spent on London construction sites, spending their time in endless hard work for a rather low pay, but which is simply unconceivable back in Ireland, and which therefore brings a certain prospect of respectability. The two are just like many others before them, "obsessed with the idea that all knowledge lies within a woman's body, but having entered it find themselves as ignorant as before" (146). Incapable of using their hopes in a constructive way, the two are so consumed by the anger of their personal failure, fed shortly only by their "royal summer" annual searches of new lovers, until their "full of hatred" desires change gradually yet fatally into their pull to carelessness in work routine. Their effort is once again focused on earning as much as possible, and return home to make a new "even bigger splash this summer than ever before" (146). This time, their greed fails, but the family situation generated by these circumstances takes a tragi-comic turn. Cunningham loses his life on improperly secured trenches, and the news reaches his family via a telegram. James Sharkey, the school master, accepts to deliver it to the family, but finds no one in the Cunningham house, as everyone is out at the hay, the deserted space echoing the perception over the event: "There is such stillness, stillness of death, he thought, about an empty house with all its doors open on a hot day" (148). The heat of the 
day and the quiet observation of the father, "We have to do the best by him the few days more he'll be with us" (148), are then followed by a rapid succession of events, the body being brought home in only two days and finally buried in Ardcarne. What nobody in the Cunninghams took into consideration in their effort to deal with the funeral was the repercussion of such a natural action: the family has now to cover the cost of transportation beyond their financial means. A few weeks later, the Dance Committee and the priest try to support the family to work this out, and the priest has a practical way of urging everyone to come with a solution for a money collection: "The family insisted on taking the body home. Whether it was wise or foolish it is done now and the only thing we know is that the Cunninghams can't afford to fly a coffin home from England. The talk is that old Joe himself will have to go to England this winter to pay off the expense of the funeral. We all feel, I think, that there's no need for that" (149). The idea is agreed, and the collection takes place at a dance party where the local band entertains the locals: "Faith, Hope and Charity' were three old bachelor brothers, the Cryans, who played at local functions. They had been known as 'Faith, Hope and Charity' for so long that nobody now knew how their name began. Faith played the fiddle. Hope beat out the rhythm on the drums. Charity was strapped into an old accordion that was said to have come from America" (150). In this story, the dance planned to collect money results in an unusual yet necessary commemoration, illuminating a new reading of its role in traditional communities, contrasting with traditional burial rituals, yet confirming the lasting bonds with the homeland: "Emigrant wakes were more common in rural areas where the traditional funeral custom of 'waking' persisted and where attachments to the land was the strongest" (Fitzgerald and Lambkin 41). The attachment of the community to deliver the ritual is clear, but the expression of the need to support the family in a difficult financial context renders the dance party its tragi-comic character. Such view, as well as the critical look cast upon his fictional personae, allowed critical voices explore the novelist's vision behind his prose as being planned "to evict history altogether and to discover a narrative form adequate to an essentially existentialist philosophy premised on the futility of the worldly struggle and on the need to 
discover some inner authority and calm in the face of life's evanescence" (Cleary 165).

Ambivalence and ambiguity permeate stories in the High Ground collection as well; the story carrying the title of the volume shows a young male hero, Moran (name ascribed to several main characters in McGahern's fiction) who is proposed by senator Reegan to become the school principal instead of the old Master, the senator being interested to make this move and get a potentially helpful ally and support a pragmatic education for his own sons, and consequently replace the stubborn old educator whose work is jeopardized because of his alcoholism. The meeting between the former student and the aging teacher who keeps on praising him reveals well-concealed feelings of the student who sees his mentor in a completely difference stance than admiration and desire to follow his footsteps: "I had once looked to him in pure infatuation, would rush to his defence against every careless whisper. He had shone like a clear star. I was in love with what I hardly dared to hope I might become. It seemed horrible now that I might come to this" (99). The old teacher's open confession that he could not praise his own relatives is mirrored in the end by a lively discussion at the bar where Johnny Conor, a bright one too, currently working as a saw mechanic, says loudly that the "sixth class in 1933 was a great class," which makes young Moran shiver, realizing all of a sudden that "nineteen thirty-three was the year before I was born," an understanding which takes him much too close to the group he hardly feels he belongs to. While the voices of former students mingle in the gaily dialogue, the comment cast by the Master turns as a clearly naïve yet sincere kind of explanation for the intellectual success of the Irish: "Ye had the brains. There are people in this part of the country digging ditches who could have been engineers or doctors or judges or philosophers had they been given the opportunity" followed by the last response from the group:

Well, the people with the brains mostly stayed here. They had to. They had no choice. They didn't go to the cities. So the brains was passed to the next generation. Then there's the trees. There's the water. And we're very high up here. We're practically at the source of the Shannon. If I had to 
pick on one thing more than another, I'd put it down to that. I'd attribute it to the high ground. (103)

The story ends there, as if the narrator has to draw the curtain and leave the reader decode if the fragment mirrors his very thinking, or he simply uses a character to express a popular opinion in the post-war era. Despite the infused naivety, this remark suggests that locals tried to look at their own identity and get a better view on the why which made them think and act differently to their neighbours, the colonial Englishmen. In choosing to describe this scene, McGahern aligns himself to numerous migrant voices who need to validate a particular feeling: "Exiles feel, therefore, an urgent need to reconstitute broken lives, usually by choosing to see themselves as part of a triumphant ideology or a restored people" (Said 177). The reclaiming and regaining territory of initial departure and subsequent return finally stands out as well-deserved success: the writer restores his place but does that on his own terms, and takes action through fiction, and not necessarily real action. His fictional universe may oppose, sometimes conflict, and ultimately make peace with his memories "through defiance and loss" (175) until it helps the author to re-establish his position in society.

\section{Conclusions}

McGahern's stories about migrants leaving Ireland and returning home are intricately linked to the power of survival, and a simple way of living impacting many generations before. This awareness does not exclude a humorous touch, on the contrary, human experience needs humour in order to dilute subjectivity in the endless cyclical turn part of one's life, making Lightfoot in "Wheels" voice it directly over pints of Guinness as a final comment about a fellow who failed to commit suicide because the branch he chose broke and he found himself shouting for help once down the river: "Looked at with the mind, life's a joke; and felt, it's a tragedy and we know cursed nothing" (The Collected Stories 3).

Heroes alternate between confrontations with their own past, often with their family members, and with the authority of dominating institutions, such as the Catholic Church and the Garda. Examples taken 
from McGahern's short stories show that issues of memory and autobiography are raised from various viewpoints, linking evidence of childhood and adulthood experience with one's profession and social and political developments specific to generations living in the post-war Ireland. In his stories, characters are hardly heroes in the primary sense of the term; they are protagonists predominantly confronting the other, be it the Englishman, the Protestant, the father, the school master or the local priest, and sometimes failing to understand the perception of older generations who despise sheer opportunism and modern taste, even if they value family property and belongings. Working characters fail to adjust their selves to the materialist vision of a consumerist society where money can only buy cheap satisfaction, while the Irish left behind switch between their local pride upon intellect and authentic and critical knowledge versus an acceptable way of incorporating tradition into modernity. They are facets of a unique species, moving from a certain inflexibility illustrated by the novelist in an interview: "My father didn't read or didn't approve of writing, but he liked giving advice" (Collinge and Vernadakis 3) to a deep understanding upon change, life and family, taking characters into a revelation of their routine existence: "I felt a new life had already started to grow out of the ashes, out of the stupidity of human wishes" (The Collected Stories 28).

\section{Works Cited}

Akhtar, Salman. Comprehensive Dictionary of Psychoanalysis. London: Karnac, 2009.

---. Immigration and Acculturation: Mourning, Adaptation and the Next Generation. Lanham, Maryland and Plymouth, UK: Jason Aronson, 2011.

Beltsiou, Julia, ed. Immigraton in Psychoanalysis: Locating Ourselves. London and New York: Routledge, 2016.

Cleary, Joe. Outrageous Fortune: Capital and Culture in Modern Ireland. Dublin: Field Day Publications, 2007.

Collinge, Linda and Emmanuel Vernadakis. "John McGahern - b. 1934.” Journal of the Short Story in English 41 (2003). Web. 15 May 2013.

Fitzgerald, Patrick and Brian Lambkin. Migration in Irish History: 1607-2007. Basingstoke, Hampshire: Palgrave Macmillan, 2008.

Frank, Soren. Migration and Literature: Gunther Grass, Milan Kundera, Salman Rushdie and Jan Kjaerstad. New York: Pagrave Macmillan, 2008. 
Grinberg, Leon and Rebeca Grinberg. "Psychoanalytic Perspectives on Migration." Psychoanalysis and Culture: A Kleinian Perspective. Ed. David Bell. London \& New York: Karnac, 1999. 154-169.

McCarthy, Dermot. John McGahern and the Art of Memory. Bern: Peter Lang, AG, 2010.

McGahern, John. High Ground and Other Stories. London: Faber and Faber, 1985.

---. Memoir. London: Faber and Faber, 2005.

---. That They May Face the Rising Sun. London: Faber and Faber, 2002.

---. The Collected Stories. London: Faber and Faber, 1992.

Murray, Tony. London Irish Fictions: Narrative, Diaspora and Identity. Liverpool: Liverpool UP, 2012.

Phillips, Lawrence. London Narratives: Post-War Fiction and the City. London \& New York: Continuum, 2006.

Prusse, Michael J. "Art, Biography and Philosophy three aspects of John McGahern's Short Fiction as Exemplified by 'Gold Watch,' 'Like All Other Men,' and 'The White Boat."' Journal of the Short Story in English (Autumn 2009). Web. 15 Oct. 2013.

Said, Edward W. Reflections on Exile and Other Essays. Cambridge, MA: Harvard UP, 2000.

Suleiman, Susan Rubin, ed. Exile and Creativity: Signposts, Travelers, Outsiders, Backward Glances. Durham and London: Duke UP, 1998.

Summers, Frank. "Ethnic Invisibility, Identity and the Analytic Process." Psychoanalytic Psychology 31.3 (2014): 410-425. Web. 10 May 2016.

Wills, Clair. The Best Are Leaving. New York: Cambridge UP, 2015. 